\title{
Behavioural ecology of a tea pest, Andraca bipunctata (Lepidoptera: Bombycidae), in the Sub-Himalayan climate of Darjeeling (India)
}

\author{
NARAYAN GHORAI ${ }^{1}$, SRIMANTA KUMAR RAUT ${ }^{2}$ and ASIT KUMAR BHATTACHARYYA ${ }^{3}$ \\ ${ }^{1}$ Department of Zoology, Darjeeling Government College, Darjeeling 734101, West Bengal, India. \\ Present address: Department of Zoology, West Bengal State University, Barasat, 24 Paraganas (N), \\ Calcutta 700126, India \\ ${ }^{2}$ Department of Zoology, University of Calcutta, Calcutta 700019, India \\ ${ }^{3}$ Department of Zoology, Darjeeling Government College, Darjeeling 734101, West Bengal, India. \\ Present address: Department of Zoology, Yogoda Satsanga Palpara Mahavidyalaya, Palpara, \\ Midnapore, West Bengal 721458, India \\ Corresponding author: Asit Kumar Bhattacharyya, e-mail: asitzsi@yahoo.com
}

(Received on 4 April 2009; Accepted on 17 November 2010)

\begin{abstract}
The summer generation $\left(\mathrm{G}_{1}\right)$ of Andraca bipunctata Walker in Darjeeling was confined to May-December and the winter generation $\left(\mathrm{G}_{2}\right)$ extended from August to June. One female laid on average 480 and 526 eggs in $\mathrm{G}_{1}$ and $\mathrm{G}_{2}$, respectively. Larvae fed on Camellia sinensis and C. assamica leaves. Duration of $1^{\text {st }}, 2^{\text {nd }}, 3^{\text {rd }}, 4^{\text {th }}$ and $5^{\text {th }}$ instars were $7,7,6,6$ and 6 days in $\mathrm{G}_{1}$, and 20, 20, 24, 72 and 33 days in $\mathrm{G}_{2}$, respectively. Temperature seems to greatly influence the duration of its life stages. A fungus (Paecilomyces tenuipes Samson), garden lizard Calotes versicolor (Daudin), and several bird species (Stachyris nigriceps Blyth, Spelaeornis caudatus (Blyth) and Dendrocitta frontalis Horsefield) were found effective in reducing the population of $A$. bipunctata.
\end{abstract}

Keywords: Andraca bipunctata, Darjeeling, life cycle, behaviour, temperature, rainfall

\section{INTRODUCTION}

Andraca bipunctata Walker, whose larvae are commonly called 'bunch caterpillars', is a well-known tea pest in the Sub-Himalayan tea gardens of Darjeeling in West Bengal (Watt \& Mann 1903; Andrews 1921; 1931; Hainsworth 1952; Das 1956a, b; BanerJee 1983; Ghorai 1992; Panigrahi 1998; 1999; 2007). Depending upon climatic conditions, the bioecology of $A$. bipunctata varies greatly (DAS 1965; GHORAI 1992). The pest is known to occur in India, Indonesia, Taiwan, China, and Vietnam. In India, the pest is reported from Assam, Sikkim, and West Bengal. Unfortunately the pest has failed to draw the attention of entomologists, both in respect to 
bionomics and control measures. Since the occurrence and life-cycle parameters of this pest differ depending on climatic conditions, and as the Darjeeling Sub-Himalayan tea gardens are famous for production of quality tea, it is necessary to study the bio-ecological parameters of $A$. bipunctata there. Considering the above, an attempt was made to study the behavioural ecology of $A$. bipunctata under both laboratory and field conditions in the Sub-Himalayan climatic conditions of Darjeeling.

\section{MATERIAL AND METHODS}

\section{Laboratory observations}

The field laboratory was set up in a roofed enclosure, adjacent to the Happy Valley Tea Estate, Darjeeling (altitude $2100 \mathrm{~m})$. Wooden terraria $(91 \mathrm{~cm} \times 61 \mathrm{~cm} \times$ $61 \mathrm{~cm}$ ) were used for rearing the pest in the field laboratory. Floor of each terrarium was covered with loose, moist soil (layer 2-4 cm thick). The open top of each terrarium was covered with a fine nylon net $(1.0 \mathrm{~mm}$ mesh size). A few tea branches of either Assamese or Chinese varieties were kept in a conical flask containing water inside each terrarium. The tea branches thus maintained were kept fresh for 35-45 days. The old branches were periodically replaced by fresh ones when needed. Several copulating moth pairs were collected on 27 May 1991. Each moth pair was confined in a separate terrarium. A batch containing 93 eggs was selected for the present study. These eggs, kept in such conditions, gave rise to successive life stages of the summer generation $\left(\mathrm{G}_{1}\right)$. Fresh and healthy tea branches were introduced after a few days of hatching for larval feeding. A batch of 100 eggs laid by a $G_{1}$ female was selected for research on the winter generation $\left(\mathrm{G}_{2}\right)$. Fresh tea branches were weighed and kept in each terrarium for larval consumption. After larval feeding, branch weight was taken again and the leaf loss was calculated, as an estimate of the amount of the leaves consumed. Additionally, dimensions of selected larval instars were measured with the help of a digital Varnier Caliper on the first and last day of each instar.

\section{Field observations}

Extensive field surveys were conducted every 5 days from May 1991 to June 1992. Numbers of individual morphs of $A$. bipunctata (i.e. eggs, larval instars, pupae, imagos) on 5 infested tea plants were recorded and the mean was calculated to determine the rate of infestation per plant. Due attention was paid to note the natural enemies and their role in influencing the density of $A$. bipunctata.

Weather data were recorded either directly, or collected from the Meteorological Station located at the Central Potato Research Station, Darjeeling (Table 1).

\section{RESULTS}

\section{Laboratory observations}

Of the 93 selected $G_{1}$ eggs, 76 eggs hatched (Table 2) in early June 1991, and the unhatched eggs were next removed. The $1^{\text {st }}$ instar larvae moulted into $2^{\text {nd }}$ instar after 7 days and consequently into $3^{\text {rd }}$ instar after another 7 days. The following instars lasted 6 days each. The $3^{\text {rd }}$ and $4^{\text {th }}$ instar larvae moulted into $4^{\text {th }}$ and $5^{\text {th }}$ instar larvae 
Table 1. Climatic parameters of the study area from May 1991 to April 1992

\begin{tabular}{lccccc}
\hline \multirow{2}{*}{ Month } & \multicolumn{2}{c}{ Temperature $\left({ }^{\circ} \mathrm{C}\right)$} & \multicolumn{2}{c}{ Relative humidity } & $\begin{array}{c}\text { Precipitation } \\
(\mathrm{cm})\end{array}$ \\
\cline { 2 - 4 } May-91 & Max & Min & Max & Min & 25.97 \\
Jun-91 & 18.6 & 11.5 & 98.8 & 81.1 & 66.84 \\
Jul-91 & 19.3 & 13.5 & 99.5 & 90.8 & 80.72 \\
Aug-91 & 20.2 & 15.1 & 99.5 & 95.4 & 70.01 \\
Sep-91 & 19.8 & 14.6 & 99.4 & 90.1 & 58.16 \\
Oct-91 & 18.7 & 12.9 & 99.5 & 89.5 & 0.1 \\
Nov-91 & 16.9 & 9.0 & 97.6 & 80.7 & 0.18 \\
Dec-91 & 11.2 & 3.1 & 95.3 & 74.0 & 1.18 \\
Jan-92 & 8.2 & 0.5 & 95.6 & 73.1 & 0.68 \\
Feb-92 & 6.8 & -0.3 & 97.4 & 74.9 & 2.62 \\
Mar-92 & 6.4 & -0.5 & 98.7 & 80.1 & 50 \\
Apr-92 & 19.5 & 8.8 & 91.3 & 65.5 & 50.2 \\
\hline & 18.7 & 11.3 & 94.5 & 75.4 & \\
\hline
\end{tabular}

on 21 and 27 July 1991, respectively. The $5^{\text {th }}$ instar larvae completed cocoon formation on 2 August 1991. The survival rate of the first 6 individual life stages, i.e. egg to $5^{\text {th }}$ instar larva, was $\geq 80 \%$ (considering the number of the previous morph as $100 \%$ ). However, only nearly $53 \%$ of pupae metamorphosed into adults.

The $\mathrm{G}_{1}$ moths started mating $22-63 \mathrm{~h}$ after emergence. Males required almost $57 \mathrm{~h}$ to start mating, while the females took less time, $22 \mathrm{~h}$. Prior to mating, the females vibrated wings rhythmically and protracted and retracted the conical caudal part for 26-34 min, 20-30 times/min. As a result, the nearby males moved towards the female, and one male (usually the nearest one to the female) reached first and started whirling dance around her within a radius of $30 \mathrm{~cm}$. The female kept vibrating her wings vigorously and extended the genital part to its maximum limit. To facilitate copulation, the male widened its genital aperture for insertion of the protruding female genitalia. Mating was end-to-end. The moths remained in copulation for almost $18 \mathrm{~h}$. The completion of mating was indicated through the act of gradual withdrawal of the caudal-genital part of the female partner. Each individual, irrespective of sex, mated only once in its lifetime. 
The $\mathrm{G}_{1}$ female did not start oviposition immediately after mating, but 30-63 min after mating the mated females moved slowly towards the leaf margin. Egg-laying started nearly $16 \mathrm{~h}$ after mating. The prospective egg-laying female positioned herself on the upper leaf surface, so that the tip of the abdomen could reach the mid-rib of the same leaf. The oval-shaped eggs were deposited in rows. The first row lied along the mid-rib and successive rows almost parallel to the first row. After oviposition the female moved towards the tip of the lamina, along the axis of the leaf. Later on, when egg deposition in the second and subsequent rows was over, the female moved towards the mid-rib of the upper surface of tea leaves. Out of 8 mated females, 4 completed oviposition in a single night, 3 completed it in 2 consecutive nights, and only one laid eggs over 3 consecutive nights. In most cases, oviposition took place at night, but some eggs were also laid during daytime, especially during cloudy weather. If oviposition extended over 2 consecutive nights, the moths released nearly $52 \%$ eggs at first night and $48 \%$ eggs at second night. In one instance, $42 \%, 33 \%$, and $25 \%$ eggs were deposited on successive nights. The required time for deposition of a single egg varied from $40 \mathrm{~s}$ to $55 \mathrm{~s}$. A single female laid 446-502 (on average 480) eggs, and the number of eggs on a leaf varied from 72 to 189 . In all cases, more than one leaf was used for egg-laying, but a single leaf was never used for oviposition by more than one female.

For further research, 100 eggs laid by a $G_{1}$ female were selected. Only 63 eggs successfully hatched into $1^{\text {st }}$ instar $G_{2}$ larvae, and all instars lasted much longer than in $\mathrm{G}_{2}$ (Table 2). The $\mathrm{G}_{2}$ adults emerged from cocoons on 4 June 1992. The highest $(89 \%)$ and lowest $(41 \%)$ survival rates in $\mathrm{G}_{2}$ were exhibited by $1^{\text {st }}$ instar and pupa, respectively.

The newly emerged $\mathrm{G}_{2}$ moths exhibited very similar behavioural patterns during courtship and mating as those shown by $G_{1}$ adults. $G_{2}$ males started mating almost $63 \mathrm{~h}$ after emergence. The mating pairs remained in copulation for more than $22 \mathrm{~h}$.

Egg-laying started almost $23 \mathrm{~h}$ after $\mathrm{G}_{2}$ mating and the egg-laying behaviour was very similar to that described earlier. However, females required 51-58 s for deposition of an egg. The number of eggs produced by a female ranged from 476 to 546 (average 526).

Because of a shortage of males, a few females could not mate, and flied randomly for hours before depositing a good number of eggs and died. However, these eggs never hatched into larvae.

\section{Description of morphs}

Egg. The freshly laid eggs were light yellow, hard, leathery, and oval. On average, an egg was about $1.34 \mathrm{~mm}$ long, $1.12 \mathrm{~mm}$ wide, and $1.23 \mathrm{mg}$ in weight. The eggs turned reddish yellow between days 10 and 11 in $G_{1}$, and between days 31 and 32 in $\mathrm{G}_{2}$. Next, they turned grey between days 14 and 15 in summer, and between days 41 and 42 in winter. The micropylar region looked like a blackish spot at the time of hatching. Nearly $3 \%$ eggs of a clutch did not show any change of colouration and never hatched.

First instar. The $1^{\text {st }}$ instar larvae were pale yellow, with the head-capsule black, body segmentation distinct, and the crochets ill-developed. The larvae secreted a 
Table 2. Life-cycle parameters of Andraca bipunctata of the summer $\left(\mathrm{G}_{1}\right)$ and winter $\left(\mathrm{G}_{2}\right)$ generations

\begin{tabular}{|c|c|c|c|c|}
\hline Morph & Starting date & Duration (days) & $\begin{array}{l}\text { Number (\%) of } \\
\text { morphs* }\end{array}$ & $\begin{array}{l}\text { Survival rate } \\
(\%)^{* *}\end{array}$ \\
\hline \multicolumn{5}{|l|}{$G_{1}$ generation } \\
\hline Egg & 7 Jun 1991 & 24 & 93 & 81.72 \\
\hline \multicolumn{5}{|l|}{ Larva } \\
\hline $1^{\text {st }}$ instar & 1 Jul 1991 & 7 & $76(81.72)$ & 80.26 \\
\hline $2^{\text {nd }}$ instar & 8 Jul 1991 & 7 & $61(65.57)$ & 80.33 \\
\hline $3^{\text {rd }}$ instar & 15 Jul 1991 & 6 & 49 (52.69) & 87.75 \\
\hline $4^{\text {th }}$ instar & $21 \mathrm{Jul} 1991$ & 6 & $43(46.24)$ & 88.37 \\
\hline $5^{\text {th }}$ instar & 27 Jul 1991 & 6 & $38(40.86)$ & 89.47 \\
\hline Pupa (cocoon) & 2 Aug1991 & 34 & $34(36.55)$ & 52.94 \\
\hline Imago & 2 Sep 1991 & 4 & $18(19.35)$ & ND \\
\hline \multicolumn{5}{|l|}{$\mathbf{G}_{2}$ generation } \\
\hline Egg & 8 Sep 1991 & 46 & 100 & 63.00 \\
\hline \multicolumn{5}{|l|}{ Larva } \\
\hline $1^{\text {st }}$ instar & 24 Oct 1991 & 20 & $63(63.00)$ & 88.88 \\
\hline $2^{\text {nd }}$ instar & 13 Nov 1991 & 20 & $56(56.00)$ & 76.78 \\
\hline $3^{\text {rd }}$ instar & 3 Dec 1991 & 24 & $43(43.00)$ & 79.06 \\
\hline $4^{\text {th }}$ instar & 27 Dec 1991 & 72 & $34(34.00)$ & 79.41 \\
\hline $5^{\text {th }}$ instar & 8 Mar 1992 & 33 & $27(27.00)$ & 81.48 \\
\hline Pupa (cocoon) & 10 Apr 1992 & 55 & $22(22.00)$ & 40.90 \\
\hline Imago & 4 Jun 1992 & 6 & $9(9.00)$ & ND \\
\hline
\end{tabular}

* Numbers in brackets are expressed as \% of the initial number of morphs (i.e. 93 in $\mathrm{G}_{1}$ and 100 in $\mathrm{G}_{2}$ ), considered as $100 \%$.** Survival rate is expressed as $\%$ of the number of the previous morph, considered as $100 \%$. ND $=$ not determined

sticky substance forming a fine thread-like structure, which helped them in hanging in case of any accidental displacement from the leaves or twigs. Newly emerged larvae did not show any movement for $6-8 \mathrm{~h}$. Later they started to crawl but spent almost $24 \mathrm{~h}$ on the lower surface of a particular leaf. The larvae did not take any food during this period and later on started feeding from the leaf margin, on which they were lodged. The veins and venules were left, as the larvae preferred the chlorophyll- 
rich leaf lamina. As a result of feeding, the pale yellowish body colour of larvae gradually turned dark yellow.

Second instar. The larva was characterized by greyish body, with 7 longitudinal equidistant stripes: 1 mid-dorsal, and 3 lateral ones on each side of the body. The larvae made a network of innumerable mucoid threads on the leaf surface. After moulting, the larvae remained without food for the first $5 \mathrm{~h}$. Later, the larvae moved to fresh green leaves. In case of accidental slipping, the larvae spent hours hanging on the mucoid thread until they became successful in settling on stems again.

Third instar. Morphologically the $3^{\text {rd }}$ instar larva was similar to the $2^{\text {nd }}$ instar larva in having the intersegmental brownish transverse stripes. The appendages were prominent and stout and the prolegs were provided with powerful crochets.

Fourth instar. The larvae had grey to blackish body colouration, and yellow dorsal-intersegmental stripes. Ventrally, 3 prominent longitudinal stripes (1 median and 2 lateral) were present. Abdominal appendages (prolegs) terminated by powerful crochets. The larvae formed clusters on twigs and the upper surface of leaves.

Fifth instar. Fifth instar larva had curved penultimate appendages and had brighter colouration than the $4^{\text {th }}$ instar larva. Other characteristic features were similar to $4^{\text {th }}$ instar larvae. Usually the larvae formed an aggregation on the tea plant in the form of a bunch, hence the name 'bunch caterpillars'. All the larvae had 3 thoracic and 9 abdominal segments, with 3 pairs of thoracic and 5 pairs of abdominal appendages.

Moulting. Prior to moulting into the next stage, all larval stages stopped feeding for almost $24 \mathrm{~h}$. During the first quarter, the larvae excreted faecal matter frequently, and moulting started at the last quarter. Larval cuticle split at the dorsal surface of the first thoracic segment, and the next larval instar emerged within 8-12 min. The white colouration of the head-capsule of the freshly moulted larva gradually turned black. Freshly moulted $2^{\text {nd }}, 3^{\text {rd }}$ and $4^{\text {th }}$ instar larvae were generally smaller than the previous instar stages. Data on the length, width, and weight of individual instar stages are presented in Table 3.

Cocoon formation. Prior to cocoon formation, $5^{\text {th }}$ instar larvae remained motionless for $2-3 \mathrm{~h}$ and discharged faecal matter frequently. Later the larvae slowly moved to the floor of the terrarium and collected 1-2 dry tea leaves. If no dry leaves were available, the larvae took fallen green leaves, stems, twigs, or even paper strips. The $G_{1}$ larvae climbed up the branches of the tea plant with leaves in their mouth. In contrast, $G_{2}$ larvae did not climb up the branches but crawled only to a certain height ( $7-8$ inches) of the terrarium wall and started cocoon formation. For cocoon formation, the larva fixed the margin of 2 leaves with saliva. In most cases, anterior and posterior ends of the cocoon nest were left open. After placing itself inside the leaf nest, the larva started spinning the cocoon by moving its head in " 8 " pattern. It took 3-7 s to complete one such " 8 " pattern. This procedure was repeated many times and the formation of the cocoon on the anterior side was completed within 90-180 min. After fixing the anterior end of the cocoon the larva changed its position and moved towards the posterior end and continued spinning in the same manner. Inside the cocoon, the larva most probably kept itself engaged in the formation of cocoon wall at the middle portion of the leaf nest. However, the exact mechanism of 


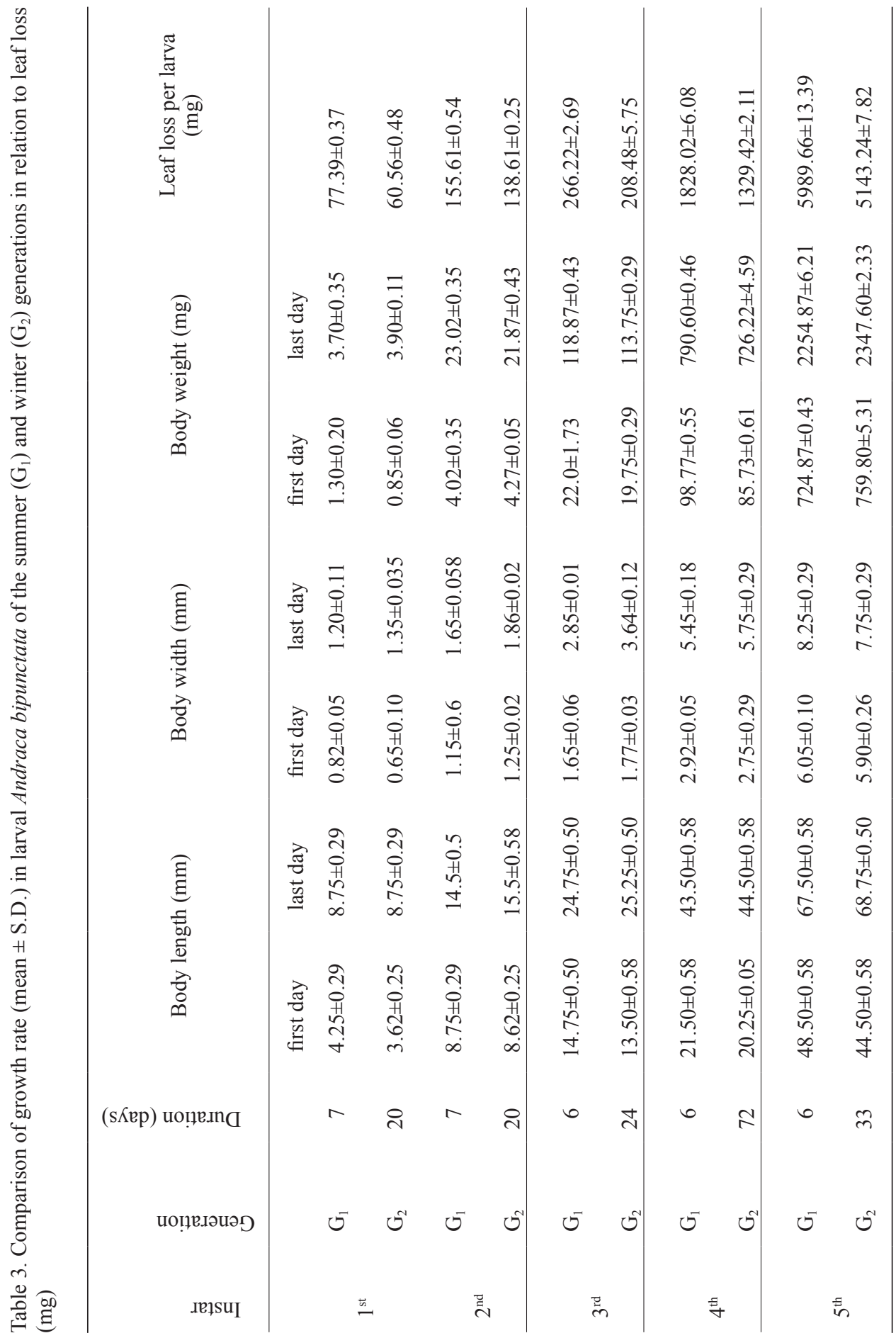


cocoon formation at the $2^{\text {nd }}$ phase is not properly known as it took place inside the leaf. Examination of the finished cocoon revealed the presence of a similar type of material knitted in the same way as seen at the anterior and posterior end of the cocoon. Complete cocoon formation took about 2.5-6 h in July-August, and 5-13 h in December-May. The longer time taken for cocoon formation by $\mathrm{G}_{2}$ larvae is probably mainly due to the low temperature from November to March. We observed that $83 \%$ of the cocoons were formed at night and the remaining was formed either in daytime or during both day and night. In most cases, one cocoon was formed by a single larva, but sometimes 2-4 larvae were also seen to form a single cocoon, and these cocoons were larger than the normal ones. On average, a single cocoon was about $29 \mathrm{~mm}$ in length, $11 \mathrm{~mm}$ in width, and $837 \mathrm{mg}$ in weight. The silken part of the cocoon was brown to dark brown.

Prepupa. After completion of cocoon formation, the larva became smaller. The $\mathrm{G}_{1}$ prepupa metamorphosed into pupa between days 7 and 8 , while the $\mathrm{G}_{2}$ prepupa metamorphosed between days 12 and 16 of cocoon formation.

Pupa. The pupa was reddish brown to dark brown. On average, a pupa was about $25 \mathrm{~mm}$ in length, $7 \mathrm{~mm}$ in width, and $720 \mathrm{mg}$ in weight. The $1^{\text {st }}$ and $2^{\text {nd }}$ prepupal stages lasted 21-25 and 25-39 days, respectively. The $\mathrm{G}_{1}$ and $\mathrm{G}_{2}$ cocoons lasted 28-44 days and 39-59 days, respectively.

Emergence of adults. Prior to emergence, A. bipunctata produced an alkaline secretion ( $\mathrm{pH}$ 9.4) to moisten the cocoon wall, usually at a point very close to the pupal head. After a few lateral body movements, the moth emerged from the cocoon. Generally the males emerged first. The newly emerged moths took rest for 15-25 min, with their wings spread horizontally. This was followed by crawling on the terrarium wall for 5-10 min, after which they moved to the tea branches and walls of the flask with water. The adults did not show any sign of feeding and preferred shady, dark places for resting.

Male moth. The male moth was dark-rusty in colour, with reddish wing underside. The antennae were dark-brown and bipectinate. Wing expanse and average body weight varied from 4.0 to $4.6 \mathrm{~cm}$ and from 359 to $365 \mathrm{mg}$, respectively. Caudal tufts were provided with fine hair-like processes. The male moths lived shorter (2-3 days) and died soon after copulation.

Female moth. The female was pale reddish-brown, with finely pectinate white antennae. Wing expanse varied from 5.1 to $6.0 \mathrm{~cm}$. Average body weight varied from 631 to $663 \mathrm{mg}$. Average life span of a female moth was 4-6 days. The dark rusty and pale reddish-brown colour of wing helps it to camouflage on dry leaves, by which they can avoid being detected by the predators.

Food consumption. Irrespective of instar stages, a larva consumed on average nearly 8317 and $6880 \mathrm{mg}$ tea leaves during $\mathrm{G}_{1}$ and $\mathrm{G}_{2}$, respectively. On average, a larva consumed 260 and $50 \mathrm{mg}$ leaves per day in $\mathrm{G}_{1}$ and $\mathrm{G}_{2}$, respectively (Table 3 ). However, in total 97122.80 and $83744.28 \mathrm{mg}$ of tea leaves per 20 larvae were lost in $\mathrm{G}_{1}$ and $\mathrm{G}_{2}$, respectively (Table 4 ), due to differences in duration of individual life stages and larval mortality. No significant difference in leaf loss due to A. bipunctata was observed between Chinese and Assamese tea plants (data not shown). 
Table 3. Loss of tea leaves due to feeding of Andraca bipunctata (the initial number of larvae was 20 , but it gradually decreased during the experiment due to larval mortality)

\begin{tabular}{lrr}
\hline \multirow{2}{*}{ Instar } & \multicolumn{2}{c}{ Leaf loss per 20 larvae $(\mathrm{mg})$} \\
\cline { 2 - 3 } & $\mathrm{G}_{1}$ (summer) & $\mathrm{G}_{2}$ (winter) \\
\hline $1^{\text {st }}$ & 0.00 & 0.00 \\
$2^{\text {nd }}$ & 124.00 & 95.24 \\
$3^{\text {rd }}$ & 2010.00 & 1804.42 \\
$4^{\text {th }}$ & 19712.00 & 13421.25 \\
$5^{\text {th }}$ & 77085.00 & 68423.37 \\
\hline Total & 97122.80 & 83744.28 \\
\hline
\end{tabular}

\section{Field observations}

Host plants. Occurrence of $A$. bipunctata was noted on cultivated tea shrubs of two varieties: Camellia sinensis var. sinensis (Chinese variety) and $C$. sinensis var. assamica (Assamese variety). Moreover, this species was also recorded on $C$. japonica and $C$. drupifera in adjacent areas.

Population density. The mean numbers of eggs, larvae (all instar stages jointly) and pupae (based on the number of cocoons) noted per plant during the present study are shown in Fig. 1. Larval morphs irrespective of instar stages were found almost throughout the year. However, larval density per infested plant varied with seasonal climatic factors (Fig. 2).

Natural enemies. The fungus Paecilomyces tenuipes (Peck) Samson attacked pupae and they died within a fortnight. Mortality rate of A. bipunctata pupae due to infestation by $P$. tenuipes fungus in the Happy Valley Tea Estate reached 20-100\% (GHORAI \& BERA 1999). The bacterium Bacillus thuringiensis (var. kurustaki) attacked some larvae and the infected larvae died invariably. Moreover, tachinid flies laid eggs on $A$. bipunctata larvae and the hatched tachinid larvae fed on the flesh of A. bipunctata larvae. Garden lizards [Calotes versicolor (Daudin)] and several bird species [Red-fronted Babbler (Stachyris nigriceps Blyth), Tailed Wren Babbler (Spelaeornis caudatus (Blyth), Black-browed Tree Pie (Dendrocitta frontalis Horsefield)] fed on adult $A$. bipunctata regularly during sunny days, when they rested on the upper surface of tea leaves.

Types of damage. Aggregations of $1^{\text {st }}$ and $2^{\text {nd }}$ instar larvae on the underside of tea leaves were noted during the study period, and these larvae started feeding from the leaf margin, ultimately devouring the entire leaf and leaving only the veins and venules. The larvae showed preference for tender leaves and twigs. From $3^{\text {rd }}$ instar onwards, the larvae started moving to the neighbouring tea branches for feeding, and 


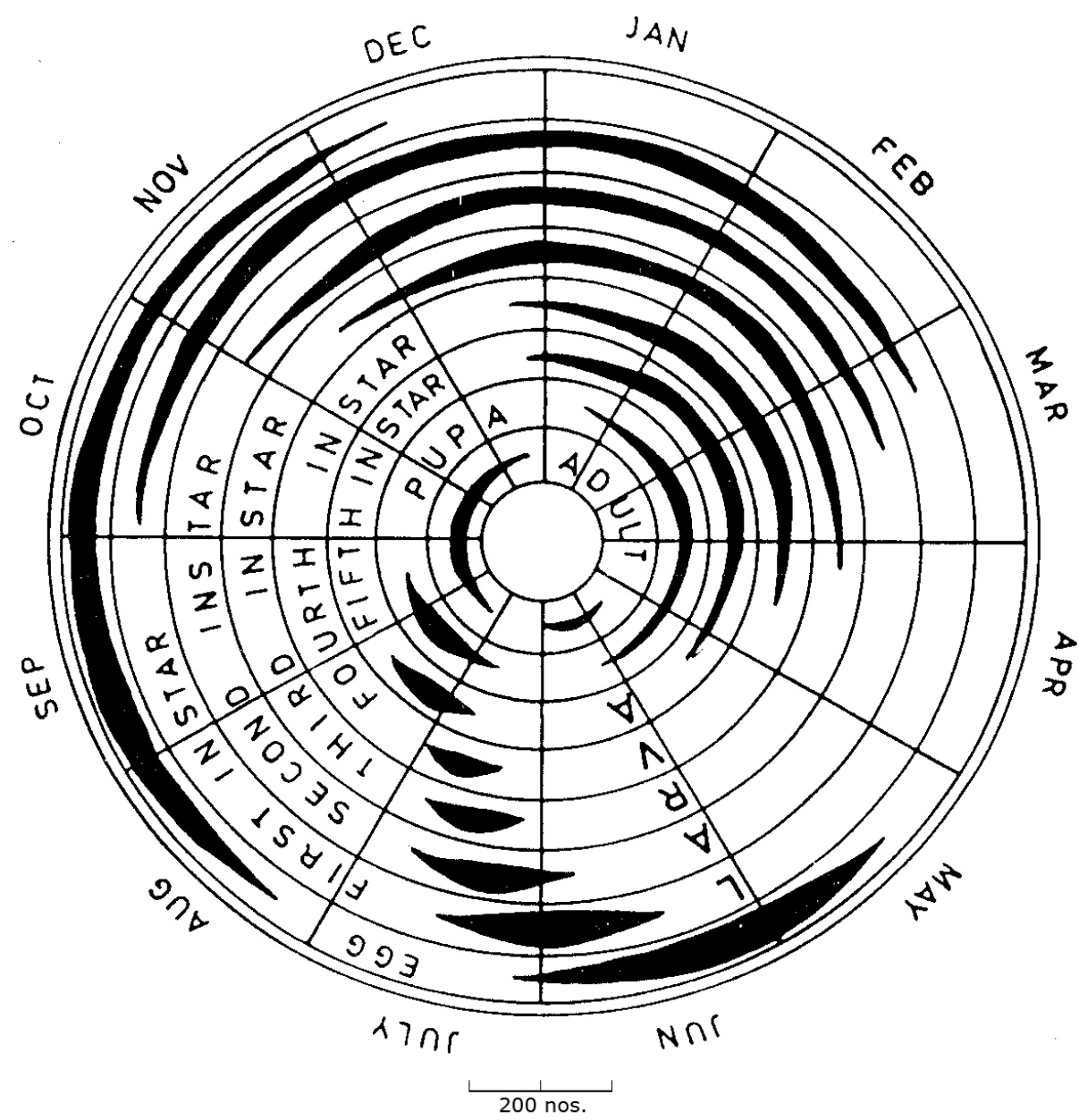

Fig. 1. Annual population dynamics: thickness of dark area indicates population density

frequently changed the plants after eating all leaves. Usually the plants adjacent to the deserted one were selected by the larvae. Owing to stunted growth, the infested plant remained unproductive for nearly 2 years.

\section{DISCUSSION}

In Darjeeling, A. bipunctata completed 2 generations annually. $\mathrm{G}_{1}$ started in summer (May-June), whereas $\mathrm{G}_{2}$ started at the onset of winter (August-December). $\mathrm{G}_{1}$ was usually completed within 93 days, while $\mathrm{G}_{2}$ took much longer time (on average 276 days). It is evident that the eggs, all larval stages, and $\mathrm{G}_{2}$ pupae required 


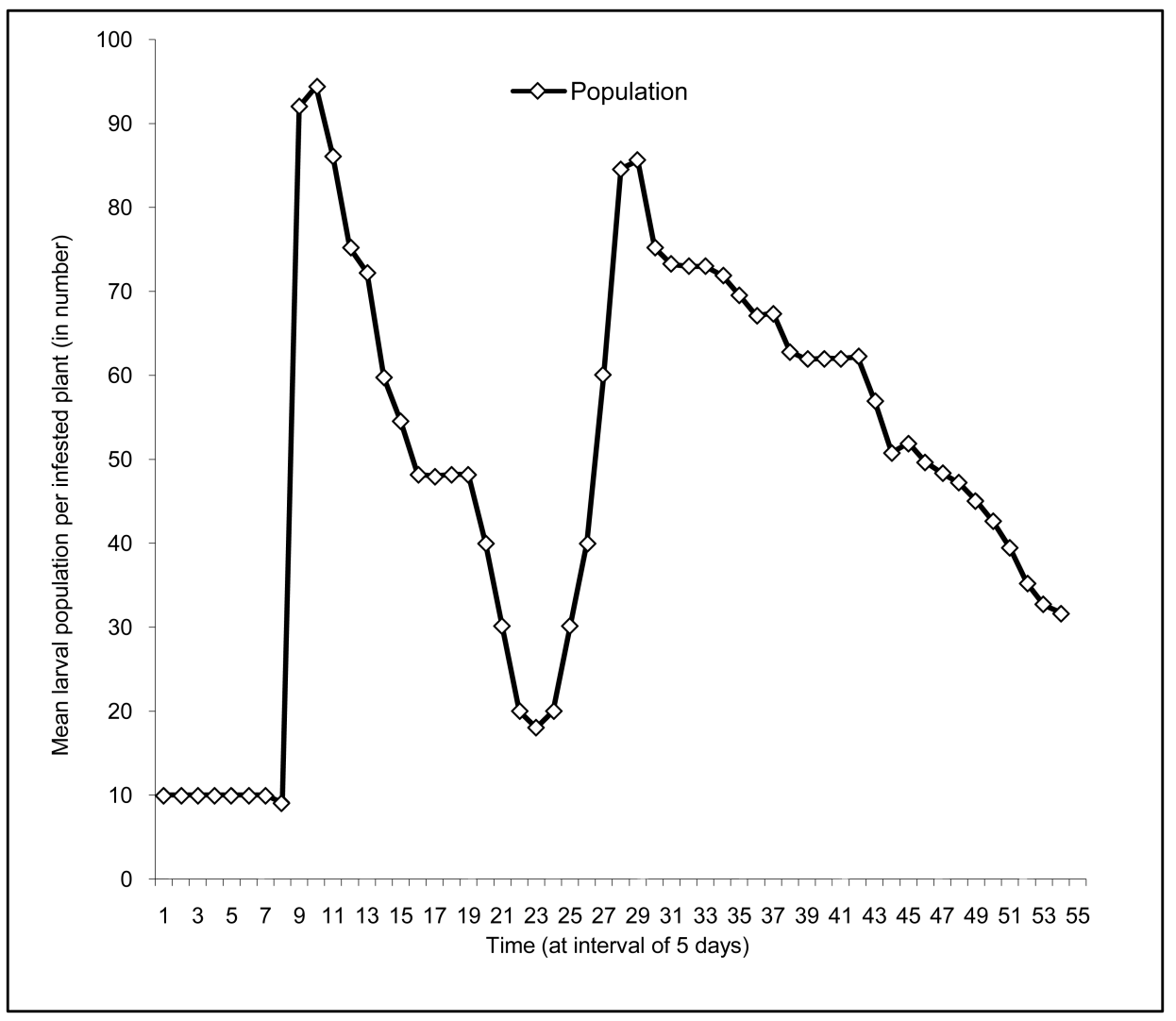

Fig. 2. Larval density per infested plant

$22,13,13,18,66,27$ and 23 days more than those of the $G_{1}$ morphs. The life span of $\mathrm{G}_{2}$ moths was nearly 2 days longer than that of the $\mathrm{G}_{1}$ moths. Such a remarkable variation in the duration of life stages seems to be due to the influence of prevailing weather conditions. Hatching and survival rate of eggs and all larval stages were generally higher in the $G_{1}$ generation. However, the survival rate of $1^{\text {st }}$ instar $G_{2}$ larvae was found to be markedly higher than in $\mathrm{G}_{1}$ (Table 2).

During $\mathrm{G}_{1}$ (7 June to 8 September 1991) the area received rainfall on 87 days out of the 94 days, the amount of daily rainfall being between 0.6 and $140.2 \mathrm{~mm}$, while during $\mathrm{G}_{2}$, rainfall was limited to only 64 days out of 276 days (8 September 1991 to 9 June 1992). In contrast to low relative humidity for a few hours of a day during $\mathrm{G}_{2}$, relative humidity throughout $\mathrm{G}_{1}$ was $100 \%$ for $19-22 \mathrm{~h} /$ day, and the overall mean relative humidity was more than $80 \%$. Therefore it seems that the variation in the duration of $\mathrm{G}_{1}$ and $\mathrm{G}_{2}$ could be partly due to the effect of relative humidity but mostly 
to some other factors. During our study, minimum temperature varied from -3.0 to $17.0^{\circ} \mathrm{C}$ and maximum temperature from 2.0 to $24.0^{\circ} \mathrm{C}$. During the summer generation $\left(\mathrm{G}_{1}\right)$, minimum temperature was $9.0-16.0^{\circ} \mathrm{C}$ and the maximum temperature was $14.0-24.0^{\circ} \mathrm{C}$, except a few days when the temperature never dropped below $13^{\circ} \mathrm{C}$. By contrast, in the winter generation $\left(\mathrm{G}_{2}\right)$ the temperature was mostly below $7^{\circ} \mathrm{C}$, and the minimum and maximum temperature was -3.0 to $14.0^{\circ} \mathrm{C}$ and 3.0 to $23.0^{\circ} \mathrm{C}$, respectively. During winter sometimes the minimum temperature fell below $0^{\circ} \mathrm{C}$, and the maximum temperature was never higher than $4^{\circ} \mathrm{C}$. Since the temperature was higher during $\mathrm{G}_{1}$ and lower during $\mathrm{G}_{2}$, it can be concluded that temperature obviously regulated the developmental processes in A. bipunctata. At low temperature, development took a long time but during warmer conditions it was just the opposite. Since in Darjeeling this pest thrived well below $0^{\circ} \mathrm{C}$ and its morphs were able to complete their development within a relatively shorter time during the warmer period, it is expected that $A$. bipunctata would be able to produce more than 2 generations under favourable conditions. A similar phenomenon was also reported from Jorhat (Assam), where A. bipunctata completed 4 generations annually (ANDREws 1931). At Jorhat, temperature ranges between 25.0 and $32.6^{\circ} \mathrm{C}$ in summer, and between 10.5 and $24.0^{\circ} \mathrm{C}$ in winter. This pest was able to complete a generation there within 8,12 , and 22 weeks during summer, pre-winter and winter, respectively (ANDREws 1931). The pupae required 68-120 days for metamorphosis into adults during cold weather (ANDREWS 1931). It appears that temperature as a key factor that regulates the duration of the life cycle of $A$. bipunctata. Therefore, it is most likely that in the tea gardens where the local meteorological conditions favour producing more than 2 generations, $A$. bipunctata would definitely turn to be a major pest causing serious damage at an equal rate throughout the year.

In spite of completing 4 generations annually in Jorhat (Assam), A. bipunctata was not able to produce more than 2 generations in Darjeeling. Taxonomically, $A n-$ draca species occurring in the tea gardens of Assam and Darjeeling are conspecific, but ecologically the Assam group is adapted to the warmer weather conditions, while the Darjeeling group is acclimatized to high altitudes. It is yet to be studied whether pests of one such group are able to survive under the conditions occupied by other groups and vice versa. Since A. bipunctata occurring in Assam requires 47 days in summer and around 170 days in winter to complete a generation instead of 94 and 276 days required by their conspecific group at Darjeeling, it can be safely concluded that $A$. bipunctata is able to thrive under such extremely variable ecological conditions. In some moth species, either eggs or larvae or pupae are well-adapted to overcome the adverse climatic conditions, but it is interesting to note that in A. bipunctata all the juvenile morphs, i.e. eggs, larvae and pupae, are well-adapted to overcome the adverse climatic conditions. As the adverse climatic conditions in the present study were mostly triggered by low temperature, it is clear that if A. bipunctata is accidentally introduced in any tea-growing regions of the world with cold climatic conditions, it would not face any problem in maintaining its generations. In Darjeeling, A. bipunctata laid eggs in May-June and August-December, and the duration of the oviposition period was more than double in the winter generation than in the summer generation. This phenomenon is very much related to the number of adult moths 
taking part in production of eggs in each generation: during the summer generation there is a possibility of getting 18 adults out of every 93 eggs, and the emergence of adults is continued for around 99 days (September-December), in contrast to the appearance of only 9 adults out of 100 eggs during 35 days of emergence in the winter generation. As a result, numbers of eggs, larvae, and pupae are expected to be much higher in summer than in winter.

The larvae of $A$. bipunctata are of serious concern from the economic point of view. Irrespective of time and instar stages, a considerable number of larvae was always found feeding on tea plants during summer (48-93 larvae per plant) and winter (25-67 larvae per plant). The total amount of consumed leaves (Table 4) was also higher in summer (97122.80 $\mathrm{mg}$ per 20 larvae) than in winter $(83744.28 \mathrm{mg}$ per 20 larvae). Larval size, weight, and total leaf loss did not differ depending on tea variety (Chinese vs. Assamese, data not shown), although the affinity of a species to a particular host plant is well-documented (KuMATA 1993). Experimentally it was observed that total leaf loss was not only due to the amount of tea leaves consumed by all larval stages but also to the loss of leaves falling due to feeding. The amount of such losses, sometimes, reached close to $50 \%$. The overall effect of feeding could also be partly accountable to the growth retardation of infested tea plants.

Tea gardens situated on Darjeeling hills are famous for production of Darjeeling Tea, which is in heavy demand all over the world. Misty weather, heavy rainfall and cold climatic conditions help in the maintenance of certain characteristic attributes of Darjeeling Tea. Happy Valley Tea Estate is one of the very few tea gardens that have adopted the policy of using only organic manures and biopesticides for production of bio-tea. Since even very small traces of pesticides in tea reduce its commercial value in the foreign market, most tea gardens of Darjeeling have undertaken the policy of not using any inorganic pesticides. The climatic factors are definitely a prerequisite for production of best quality tea but it is also equally true that these factors do not pose any threat to $A$. bipunctata for continuation of any of its 2 generations. In an effort to survive in such adverse climatic conditions, all life stages in general and $\mathrm{G}_{2}$ individuals in particular follow 'making-the-best-of-the-worst-situation' strategy and somehow manage to survive by lengthening the duration of each stage. Keeping this in mind, it is necessary to formulate and introduce strict control measures to check their further population growth. Since the application of inorganic pesticides is not desirable because of their health, environmental, as well as commercial implications, emphasis should be given on bio-control measures. It is noted that damages to the plants were exclusively caused by larvae, since the adults hardly caused any damage. Lizards and birds preyed on the adults but full-fledged control by these agents does not seem to be effective. The adults also enjoy the advantage of not being detected because of the highly developed camouflaging skills. Caterpillars forming clusters on upper leaf surface could not be detected because of the bushy nature of tea plants.

Several researchers (SHIMADA 1980; TAMAKI et al. 1980; HoRIKAWA et al. 1986; HiYORI et al. 1986; OTAISHI et al. 1991) worked on the pheromone-related control measures of another important pest of tea, smaller tea tortrix moth (Adoxophyes sp.) but to date no exclusive study on Andraca bipunctata has been carried out. In our opinion, A. bipunctata can be most effectively controlled by the judicious use of the 
fungus Paecilomyces tenuipes (Peck) Samson. The fungus is known to have a $100 \%$ efficient control measure performance (GHORAI \& BERA 1999).

Acknowledgements: We appreciate the assistance offered by Dr S. Sheela, Mr Amitava Roy, and Mr Sunando Mukherjee of the Zoological Survey of India, Calcutta, and Mr Bikash Ghorai of Y.S. Palpara Mahavidyalaya for their help during the preparation of the manuscript. Support provided by the Happy Valley Tea Estate authority is also gratefully acknowledged. A.K.B. thanks the Principal, Y. S. Palpara Mahavidyalaya, for providing necessary facilities.

\section{REFERENCES}

ANDREws E. A. 1921. A preliminary pest calendar for the tea districts of north-east India. Q. J. Indian Tea Assoc. 13: 149-167.

ANDREws E. A. 1931. Caterpillar pests of the tea plant, and of green manure plants and shade trees in use of tea estates. Q. J. Indian Tea Assoc. 19: 189-202.

BANERJEe B. 1983. Arthropod accumulation on tea in young and old habitats. Ecol. Entomol. 8: 117-23.

Das G. M. 1956a. New psychids (Lep. Psychidae) from Assam. Ann. Mag. Nat. Hist. 9: 186-190.

DAs G. M. 1956b. Psychidae (Lepidoptera) on the tea in north-east India. Ann. Mag. Nat. Hist. 9: 569-576.

DAS G. M. 1965. Pests of tea in north-east India and their control. Tea Research Association, Tocklai Experimental Station, Cinnamara, Assam, India. Memorandum No. 27.

Ghorai N. 1992. Ecology of the tea pest Andraca bipunctata (Walker) (Insecta: Bombycidae). PhD thesis, University of Calcutta.

Ghorai N., Bera S. 1999. Occurrence of an entomopathogenic fungus Paecilomyces tenuipes (Peck) Samson (Deuteromycetes: Moniliaceae) on the tea bunch caterpillar Anadraca bipunctata (Walker) (Lepidoptera: Bombycidae). Sci. Cult. 65: 323-324.

Hainsworth E. 1952. Tea pests and diseases and their control. Heifer and Sons, Cambridge.

HIYORI T., KAINOH Y., NiNORNIYA Y. 1986. Wind tunnel tests on the disruption of pheromonal orientation of the male smaller tea tortrix moth, Adoxophyes sp. (Lepidoptera: Tortricidae). I. Disruptive effect of sex pheromone components. App. Entomol. Zool. 21: 153-158.

Horikawa T., Shiratori C., Suzuki T., Sone K., Muramatsu M. 1986. Evaluation of sake-lees bait as an attractant for the smaller tea tortrix moth (Adoxophyes sp.) and tea totrix moth (Homona magnanima Diakonoff). Jap. J. App. Entomol. Z. 30: 27-34 (in Japanese with English abstract).

Kumata T. 1993. A contribution to the knowledge of the Malayasian Lithocolletinae (Gracillariidae, Lepidoptera), with a revision of Indian Cameraria associated with Leguminosae. Ins. Mats. 48: $1-85$.

Otaishi M., Uсніліма J., Yамамото A. 1991. Relationship between aerial concentration of a synthetic sex pheromone component and mating in the disruption field of the smaller tea tortrix, Adoxophyes sp. (Lepidoptera: Tortricidae). Jap. J. App. Entomol Z. 35: 207-212 (in Japanese with English abstract).

Panigrahi A. 1998. Effect of relative humidity on the eggs of the tea pest, Andraca bipunctata Walker (Lepidoptera: Notodontidae). Bangladesh J Zool. 26: 103-105.

Panigrahi A. 1999. Status of larval population and damage to tea of Andraca bipunctata Walker (Lapidoptera: Notodontidae) at Darjeeling Himalayan region. Ecol. Environ. Conserv. 5: $111-113$.

PANigrahi A. 2007. Effect of relative humidity on hatching of eggs of the tea pest Andraca bipunctata Walker (Lepidoptera: Notodontidae). Indian Biol. 39(2): 9-11. 
Shimada K. 1980. Sex pheromone mass trapping for control of the smaller tea tortrix. Jap. J. App. Entomol. Z. 24: 81-85 (in Japanese with English abstract).

Tamaki Y., Noguchi H., Sugie H., Kariya A., Arai S., Ohba M., Terada T., Suguro T., Mori K. 1980. Four-component synthetic sex pheromone of the smaller tortrix moth: Field evaluation of its potency as an attractant for male moths. Jap. J. App. Entomol. Z. 24: 221-228 (in Japanese with English abstract).

Watt G., Mann H. H. 1903. The pests and blights of the tea plant. 2nd ed. Calcutta, India. 